\title{
Anticancer Agents from Non-Edible Parts of Theobroma cacao \\ Zainal $\mathbf{B}^{1,3}$, Abdah MA ${ }^{1 *}$, Taufiq-Yap $\mathbf{Y H}^{2}$, Roslida $\mathrm{AH}^{1}$ and Rosmin $\mathrm{K}^{3}$
}

${ }^{1}$ Department of Biomedical Science, Faculty of Medicine and Health Sciences, University Putra Malaysia, Selangor, Malaysia

${ }^{2}$ Department of Chemistry, Faculty of Science, University Putra Malaysia, Selangor, Malaysia

${ }^{3}$ Division of Biotechnology, Centre for Cocoa Biotechnology Research, Malaysian Cocoa Board, Sabah, Malaysia

\begin{abstract}
In order to establish the medicinal properties as anticancer agents from the non-edible of cocoa plant parts, the studies on fresh of non-edible cocoa plant parts such as cocoa leaf $(\mathrm{CL})$, cocoa bark $(\mathrm{CB})$, cocoa husk $(\mathrm{CH})$, cocoa shell unfermented (CSUF), cocoa shell fermented (CSF), cocoa root (CR), cocoa cherelle (CC) \& cocoa pith (CP) were performed by extracting in methanol solvent, screening against various type of cancer cell lines, purified using bioassay guided fractionation and identified active compounds using gas chromatography-mass spectrometry (GCMS). Results revealed that the cocoa leaf extract presented the highest antiproliferative activity against breast cancer cell line (MCF-7) with $\mathrm{IC}_{50}$ value was $41.43 \pm 3.26 \mu \mathrm{g} / \mathrm{ml}$ and selected for further purification using bioassay guided fractionation. The hexane partitioned fraction of cocoa leaf showed the highest anticancer activity with $I C_{50}$ value about $66.7 \pm 7.95 \mu \mathrm{g} / \mathrm{ml}$. Hexane partitioned fraction was further purified using flash column chromatography and divided into 3 steps such as fractionation-1, fractionation-2 and fractionation-3. Sample fraction II/F7 from fractionation-2 was selected for chemical characterization using GC-MS due to the highest anticancer cancer activity with $\mathrm{IC}_{50}$ value was $6.36 \pm 0.71 \mu \mathrm{g} / \mathrm{ml}$ and generated 10 major active compounds with synergistic effect against MCF-7. Nine compounds were known compounds and one compound was unknown compound. Theobroma cacao is still an underutilized plant and its bean has been used traditionally as source of food and medicine. The consumption of cocoa leaf as non-edible part could provide health benefits especially to treat human cancer in the future.
\end{abstract}

Keywords: Theobroma cacao; Anticancer activity; Bioassay guided fractionation; Natural product; Plant extracts; Cancer cell

\section{Introduction}

T. cacao was a genus Theobroma and classified together with the genera Herrania, Guazuma, and Cola in the family Sterculiaceae. T. cacao was originated from ancient Central America where the civilizations of Maya and Aztecs cultivated it for its seeds (beans), which was used for drinking called chocolatl, a precursor to the modern chocolate [1]. Peoples from Olmec and Mayan believed that cacao bean had a divine origin and belief it as "food of the gods". Based on the scientific name of Theobroma, Theo is meaning "food" and Broma is meaning "gods" [2,3]. More than 100 medicinal uses for cocoa were described in manuscripts produced from over 3000 years ago to the present and cocoa has been used to treat anemia, mental fatigue, tuberculosis, fever, gout, kidney stones, and even poor sexual appetite [4]. Cocoa phytochemical contained various health effects, including improved heart function, relief of angina pectoris, and stimulant of the nervous system, facilitated digestion, improved kidney and bowel function [4]. Recent investigation on Panama's Kuna Indian population revealed that Kuna Indians living on the islands, and heavy consumers of cocoa, had significantly lower rates of heart disease, cancer, and diabetes mellitus compared to those on the mainland, who do not consume cocoa [5]. This was suggesting that cocoa might be useful in the prevention of heart disease, cancer, and diabetes mellitus. Principally, cocoa contains high active compounds such as theobromine, flavonoids(-)-epicatechin, (+)-catechin and their dimers procyanidins $\mathrm{B} 2$ ( $\mathrm{PB} 2)$ and $\mathrm{B} 1$, although other polyphenols such as quercetin, isoquercitrin (quercetin3-O-glucosi de), quercetin 3-O-arabinose, hyperoside (quercetin 3-O-galacto side), naringenin, luteolin and apigenin have also been found in minor quantities [6].

Cancer chemopreventive activity of cocoa has been reported that cocoa liquor procyanidins significantly reduced the incidence and multiplicity of lung carcinomas and also decreased thyroid adenomas developed in male rats [7]. Selected procyanidins present in cocoa inhibit tumorigenesis, tumor growth, and angiogenesis [8]. Consumption of cocoa or dark chocolate can also decrease the burden and efficacy of epigenetic carcinogens [9]. Procyanidin-enriched cocoa seed extracts caused G2/M cell cycle arrest and 70\% growth inhibition in Caco-2 colon cancer cells [10]. On the other hand, cocoa-derived pentameric procyanidin caused G0/G1 cell cycle arrest and selective growth inhibition in human breast cancer cells [11]. It has been also found that cocoa procyanidins reduce vascular endothelial growth factor activity and angiogenic activity associated with tumor pathology [8]. Fundamental mechanisms of carcinogenesis are associated with ROS, and population studies have demonstrated that people with a regular intake of foods containing antioxidants, such as vegetables, fruits, tea, or soy products, display a lower incidence of various types of cancer $[9,12]$. It can be postulated, therefore, that consumption of cocoa or chocolate, which have high antioxidant activity, could be beneficial in decreasing the damage from genotoxic and epigenetic carcinogens, and inhibiting the complex processes leading to cancer. Prevention of cancer through the diet is receiving increasing interest, and cocoa because of its polyphenolic compounds has become an important potential chemopreventive and therapeutic natural agent. Cocoa and its main polyphenols have been reported to interfere at the initiation, promotion and progression of cancer. Cocoa flavonoids demonstrated that influenced several important biological activities in vitro and in vivo by their free radical scavenging ability or through the regulation of signal transduction pathways to stimulate apoptosis, inhibit inflammation, cellular proliferation, apoptosis, angiogenesis and metastasis [13]. Nevertheless, these molecular mechanisms of action are not completely characterized and many features remain to be elucidated. The objective for this study is to purify and identify

*Corresponding author: Abdah MA, Department of Biomedical Science, Faculty of Medicine and Health Sciences, University Putra Malaysia, 43400 UPM, Serdang, Selangor, Malaysia, Tel: +6-01-2217-9460; E-mail: abdah@upm.edu.my

Received March 19, 2014; Accepted April 29, 2014; Published April 30, 2014

Citation: Zainal B, Abdah MA, Taufiq-Yap YH, Roslida AH, Rosmin K (2014) Anticancer Agents from Non-Edible Parts of Theobroma cacao. Nat Prod Chem Res 2 :134. doi:10.4172/2329-6836.1000134

Copyright: @ 2014 Zainal B, et al. This is an open-access article distributed under the terms of the Creative Commons Attribution License, which permits unrestricted use, distribution, and reproduction in any medium, provided the original author and source are credited. 
the anticancer agents from non-edible parts of Theobroma cacao with potent anticancer activity.

\section{Material and Methods}

\section{Plant materials}

The fresh of non-edible cocoa plant parts such as cocoa leaf (CL), cocoa bark (CB), cocoa husk (CH), cocoa shell unfermented (CSUF), cocoa shell fermented (CSF), cocoa root (CR), cocoa cherelle (CC) \& cocoa pith (CP) were collected from Research Field of Malaysian Cocoa Board at Ranau, Sabah, Malaysia. Plant samples collected during peak season of cocoa fruit on April. The fresh cocoa plant parts were harvested, rinsed under tap water and air dried followed by oven dried at $40^{\circ} \mathrm{C}$ for 5 days. Then, the samples were grinded using commercial blender (Waring). Each $5 \mathrm{~g}$ powder plant part was extracted by soaked in $200 \mathrm{ml}$ methanol for 3 days at room temperature. The mixture was then filtered using a clean muslin cloth and then, Whattman Nol. filter paper. The filtrate was then evaporated to dryness using a rotary evaporator attached to a vacuum pump. Extract was stored at 2 to $8^{\circ} \mathrm{C}$ until further used. To test the biological activity, $10 \mathrm{mg}$ of dried crude extracts were dissolved in $1 \mathrm{ml}$ dimethyl sulfoxide (DMSO) to produce $10 \mathrm{mg} / \mathrm{ml}$ concentration of stock solution. This stock solution of crude extracts were later mixed with culture media (DMEM or RPMI 1640) to achieve the desired concentration of $1000,100,10,1,0.1,0.01$ and $0.001 \mu \mathrm{g} / \mathrm{ml}$ using 10 fold serial dilutions and stock solution of fractions were started with desired concentration from 100 to 0.0001 $\mu \mathrm{g} / \mathrm{ml}$ using 10 fold dilutions.

\section{Human cell lines and cell culture preparation}

Cancer cell lines used in this study were breast with estrogen receptor positive (MCF-7), breast with estrogen receptor negative (MDA-MB-231), liver (HepG2), colon carcinoma (HT-29), lung (A549) and cervical (HeLa) cell lines. Normal cell line was liver (WRL-68). Colon (HT-29) and breast with estrogen receptor negative (MDA-MB-231) cancer cell lines were cultured in 89\% Modified Eagle Dulbecco's Medium (DMEM) with 10\% Fetal Bovine Serum (FBS) and $1 \%$ penicillin/Streptomycin. While, breast with estrogen receptor positive (MCF-7), liver (HepG2), cervical (HeLa) and lung (A549) cancer cell lines were cultured in 89\% RPMI 1640 with 10\% Fetal Bovine Serum (FBS) and 1\% penicillin/Streptomycin. Both of these cells were cultured at $37^{\circ} \mathrm{C}$ at a humidity of $95 \%$ and $5 \% \mathrm{CO}_{2}$ for 3 days until confluent cell culture was $80-90 \%$. After that the old medium was removed, replaced with new medium and incubated again for 24 hours. The cell culture was then washed with PBS 1-2 times and suspended using trypsin-EDTA solution. Cells that were suspended coupled with new media.

\section{Media, chemicals and reagents}

Silica gel 60 (particle size 0.040-0.063 mm, 230-400 mesh ASTM) was purchased from Merck, Germany, Thiazolyl Blue Tetrazolium Bromide (MTT), dimethyl sulfoxide (DMSO), Trypan blue $(0.4 \%)$ and phosphate buffered saline (PBS) were purchased from Sigma Chemical Co. USA. Roswell Park Media Institute (RPMI) 1640, penicillin/streptomycin (100x), trypsin-EDTA (1x) and fetal bovine serum mycoplex (FBS) were obtained from PAA, GMBH, (Germany). Hexane, methanol, dichloromethane, ethyl acetate and chloroform used were of the highest pure grade obtained from Fisher, UK. Iodine resublimed was purchased R\& M Chemicals, Essex, UK.

\section{MTT assay}

Antiproliferative effect of cocoa extracts and fractions were determined in vitro against cancer cell lines using the microtitration colorimetric method of MTT reduction [14] with minor modification. The tetrazolium salt 3-[4,5-dimethylthiazol-2-yl]2,5-diphenyltetrazolium bromide (MTT) is used to determine cell viability in assays of cell proliferation and cytotoxicity. Briefly, cells were harvested from maintenance cultures in the exponential phase and counted by a hemocytometer using trypan blue solution after the cells reached $80-90 \%$ confluency. The cell suspensions were dispensed $(100 \mu \mathrm{L})$ in triplicate into 96-well culture plates at optimized concentration about $1.0 \times 10^{5}$ cells $/ \mathrm{ml}$ for each cancer cell line. After 24 hours incubation at $37^{\circ} \mathrm{C}, 100 \mu \mathrm{L}$ cultured medium was removed from the well and $100 \mu \mathrm{L}$ fresh medium containing series concentrations of cocoa plant part extracts were added to each well and incubated for another 48 hours. The RPMI 1640 used as negative control. After treatment period, the medium in each well was aspirated and replaced with $20 \mu \mathrm{l}$ of $5 \mathrm{mg}$ MTT working solution (MTT) stock solution mixed with medium to attain a final concentration of $0.5 \mathrm{mg} / \mathrm{ml}$. MTT powder was dissolved in PBS to form a stock solution of MTT ( $5 \mathrm{mg} / \mathrm{ml})$. The stock solution was filter-sterilized through a $0.22 \mu \mathrm{m}$ filter and stored at $-20^{\circ} \mathrm{C}$. The cells were incubated at $37^{\circ} \mathrm{C}$ for 4 hours and then the medium was aspirated and replaced with $100 \mu \mathrm{l}$ DMSO to dissolve the formazan crystals formed. The culture plates were shaken for $5 \mathrm{~min}$ and the absorbance (OD) of each well was read using Elisa Reader at 570 $\mathrm{nm}$ with $630 \mathrm{~nm}$ as the reference wavelength. The dose-response curves of the cocoa fractions were fitted by means of the computer programme Graph Pad Prism 5.02 (Graph Pad Software, San Diego, CA, USA) and $\mathrm{IC}_{50}$ (the concentration of sample needed to reduce a $50 \%$ absorbance relative to the vehicle-treated control) values were calculated.

\section{Plant extraction and fractionation preparation}

Extraction process were followed based on Pan et al.; Ludwiczuk et al. and Forgo et al. [15-17] methods with some modification. The dried and ground active cocoa plant part (1 kg) of Theobroma cacao was extracted with methanol $(10 \mathrm{~L})$ by soaking in room temperature for 3 days. After filtration using white cloth, the liquid phase was pooled and concentrated by evaporated under vacuum using rotary evaporator at $40^{\circ} \mathrm{C}$ to yield a methanolic crude extract of cocoa leaf. The methanolic crude extract was extracted by successive liquid-liquid partition with hexane $(250 \mathrm{ml})$ followed by dichloromethane $(250 \mathrm{ml})$ and lastly methanol $(250 \mathrm{ml})$ to yield 3 partitioned fractions. The hexane, dichloromethane and methanol partitioned fractions were obtained after filtered using vacuum filter and evaporated under reduced pressure. The partitioned fractions with potent antiproliferative activity were subjected to flash column chromatography based on Lai et al. and Ode et al. $[18,19]$ methods with some modification to separate the extract into its component fractions. Silica gel $60 \mathrm{G}$ was used as the stationary phase while varying solvent combinations of increasing polarity were used as the mobile phase. In the setting up of column chromatography, the lower part of the glass column was stocked with glass wool with the aid of glass rod. The slurry prepared by mixing silica gel $80 \mathrm{~g}$ (fractionation-1), $30 \mathrm{~g}$ (fractionation-2) and $10 \mathrm{~g}$ (fractionation-3) with hexane of $250 \mathrm{ml}, 200 \mathrm{ml}$ and $150 \mathrm{ml}$ respectively and poured down carefully into the column. The tap of the glass column was left open to allow free flow of solvent into a conical flask below. The set-up was seen to be in order when the solvent drained freely without carrying either the silica gel or glass wool into the tap. At the end of the packing process, the tap was locked. The column was allowed 24 $\mathrm{h}$ to stabilize, after which, the clear solvent on top of the silica gel was allowed to drain down to the silica gel meniscus. The wet packing method was used in preparing the silica gel column. The sample was mixed with silica gel $5.0 \mathrm{~g}$ (fractionation-1), $3 \mathrm{~g}$ (fractionation-2) and 
$1 \mathrm{~g}$ (fractionation-3) in hexane and dried at room temperature for 24 hours. The dry powder was shaken softly and then gently layered on top of the column. The column tap was opened to allow the eluent to flow at the rate of 40 drops per minute. Elution of the extract was done with solvent systems of gradually increasing polarity were sequentially used in the elution process; Step 1: hexane (100\% v), step 2: Hexane: DCM (4:1 v/v), step 3: Hexane: DCM (3:2 v/v), step 4: Hexane: DCM $(2: 3 \mathrm{v} / \mathrm{v})$, step 5: Hexane: DCM (1:4 v/v), step 6: DCM (100\%), step 7: DCM: $\mathrm{MeOH}(4: 1 \mathrm{v} / \mathrm{v})$, step 8: DCM: $\mathrm{MeOH}(3: 2 \mathrm{v} / \mathrm{v})$, step 9: DCM: $\mathrm{MeOH}(2: 3 \mathrm{v} / \mathrm{v})$, step 10: DCM: $\mathrm{MeOH}(1: 4 \mathrm{v} / \mathrm{v})$ and finally step 11: $\mathrm{MeOH}(100 \% \mathrm{v})$. The eluted fractions were collected in aliquots of 50 $\mathrm{ml}$ (fractionation-1), $10 \mathrm{ml}$ (fractionation-2) and $5 \mathrm{ml}$ (fractionation-3) in test tubes. The chemical composition of each fraction was evaluated by using thin layer chromatography (TLC) and visualized with UV (254 and $365 \mathrm{~nm}$ ) to identify fractions containing similar constituents, which were combined. The combined fractions were evaporated in vacuo at $40^{\circ} \mathrm{C}$. The yield of crude extract, partitioned fractions and fractions were determined.

\section{Bioassay guided fractionation and isolation}

The antiproliferative effect of active non-edible methanolic plant extracts of Theobroma cacao was tested against susceptible cancer cell lines using the MTT cell viability assay to confirm the presence of anticancer activity. The methanolic extract was then partitioned in hexane, dichloromethane and methanol solvents and the resultant partitioned fractions were again tested for their antiproliferative activity. Partitioned fractions that demonstrated more than 50\% growth inhibition as determined by comparison of the $\mathrm{IC}_{50}$ values were then subjected to separation using silica gel chromatography, affording a series of fractions. In the same way, each fraction obtained from the flash column chromatography was likewise assayed for selective antiproliferative activity on susceptible cancer cell line and this was used to select fractions for further flash column chromatography. The inactive extracts and fractions were set aside and not subjected to further study in this work.

\section{Phytochemical screening}

Preliminary phytochemical analysis methanolic cocoa leaf extract and hexanolic cocoa leaf partitioned fraction of Theobroma cacao with high anticancer activity was carried out based on $5.0 \mathrm{~g}$ of dried powder material to identify the presence of some phytochemical constituents that usually exhibit biological activities such alkaloids, flavonoids, saponins, tannins, triterpines \& steroids. All samples were analyzed in the Laboratory of Phytomedicine, Forest Research Institute of Malaysia, Kepong, Malaysia.

\section{Gas chromatography-mass spectrometry (GC-MS)}

Most active fraction was analyzed using GC-MS and carried out by following the method of Hema et al. [20] with some modification. GCMS analysis were performed using a QP2010 Plus Shimadzu system and gas chromatograph interfaced to a Mass spectrometer (GC-MS) equipped with a SGE BPX5, fused silica capillary column (30m x 0.25 mm ID x $0.25 \mu \mathrm{m}$ ), composed of $100 \%$ Dimethyl poly siloxane). For GC/MS detection, an electron ionization system with ionizing energy of $70 \mathrm{eV}$ was used. Helium gas (99.999\%) was used as the carrier gas at constant flow rate $1.5 \mathrm{ml} / \mathrm{min}$ and an injection volume of $0.2 \mu \mathrm{l}$ was employed split ratio of 1.0 , injector temperature $250^{\circ} \mathrm{C}$ and ion source temperature $280^{\circ} \mathrm{C}$. The oven temperature was programmed from $50^{\circ} \mathrm{C}$ (isothermal for $2 \mathrm{~min}$ ) with an increase of $50^{\circ} \mathrm{C} / \mathrm{min}$ to $200^{\circ} \mathrm{C}$, then $50 \mathrm{C} / \mathrm{min}$ to $320^{\circ} \mathrm{C}$, ending with a $9 \mathrm{~min}$ isothermal at $320^{\circ} \mathrm{C}$. Mass spectra were taken at $70 \mathrm{eV}$; a scan interval of 0.5 seconds and fragments from 30 to $750 \mathrm{~m} / \mathrm{z}$. Total GC running time was 21 minutes. The relative\% amount of each component was calculated by comparing its average peak area to the total areas, software adopted to handle mass spectra and chromatograms was a GC-MS solution. Interpretation on mass spectrum GC-MS was conducted using the database of National Institute Standard and Technology (NIST) having more than 62,000 patterns. The spectrum of the unknown component was compared with the spectrum of the known components stored in the NIST library. The name, molecular weight and structure of the components of the test materials were ascertained.

\section{Statistical analysis}

All determinations were expressed in mean \pm SEM. The MTT assays for each sample were carried out triplicates at three different days. The $\mathrm{IC}_{50}$ values were calculated using Graph Pad Prism version 5.02. Significant differences between means were determined by Tukey HSD test. A significant difference was considered at the level of $\mathrm{p}<0.05$.

\section{Results and Discussion}

\section{Screening cocoa plant parts for antiproliferative activity}

All the cocoa extracts against various cancer cell lines were evaluated based on MTT assay values and curves of percentage viability of treated cells were plotted against extracts concentration. Based on anticancer screening activities using MTT assay illustrated in Figure 1 that the extracts against cancer cell lines with $\mathrm{IC}_{50} 20$ to $100 \mu \mathrm{g} / \mathrm{ml}$ were produced from cocoa leaf $(41.43 \pm 3.260 \mu \mathrm{g} / \mathrm{ml})$ against MCF-7, bark $(71.97 \pm 9.27 \mu \mathrm{g} / \mathrm{ml})$ against MCF-7, husk $(62.23 \pm 14.90 \mu \mathrm{g} / \mathrm{ml})$ against MCF-7, shell (unfermented) $(65.03 \pm 4.17 \mu \mathrm{g} / \mathrm{ml})$ against MCF7 , shell (fermented) $(71.40 \pm 12.11$ and $68.90 \pm 10.18 \mu \mathrm{g} / \mathrm{ml})$ against HeLa and HepG2 respectively, root $(76.40 \pm 13.81 \mu \mathrm{g} / \mathrm{ml})$ against MCF-7 and cherelle $(67.80 \pm 9.36$ and $68.90 \pm 11.41 \mu \mathrm{g} / \mathrm{ml})$ against HeLa and MCF-7 respectively considered moderately active. Other cocoa extracts against cancer cell lines with $\mathrm{IC}_{50}$ values of 100 - 1000 $\mu \mathrm{g} / \mathrm{ml}$ considered weakly active. The small number of $\mathrm{IC}_{50}$ value means more potent anticancer activity as stated by Atjanasuppat et al. [21]. MTT assay is a typical method and common use in determination of anticancer activities. The cleavage of tetrazolium ring in MTT involves the mitochondrial succinate dehydrogenase and depends on the activity of the respiratory chain and the redox state of the mitochondria responsible for the production of cell energy. The exposure of cancer cells to cocoa extracts induced a significant reduction in the conversion of MTT, which means a cellular disintegration and cytotoxicity reflected from the parallel dose and time dependent decrease of the absorbance measured [22]. Based on $\mathrm{IC}_{50}$ value, cocoa leaf extract was the most potent anticancer activity against MCF-7 with $\mathrm{IC}_{50}$ value

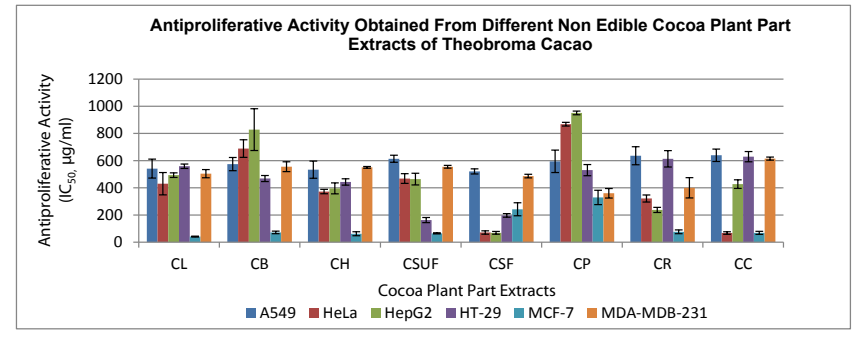

Figure 1: Anticancer activity $\left(\mathrm{IC}_{50}\right.$ values) of eight cocoa plant part extracts (Theobroma cacao) that used in the treatment of Lung (A549), cervical (HeLa), liver (HepG2), colon (HT-29), breast estrogen receptor positive (MCF-7) and breast estrogen receptor negative (MDA-MDB-123) cancer cell lines. 
about $41.43 \pm 3.26 \mu \mathrm{g} / \mathrm{ml}$ was significantly different $(\mathrm{P}<0.05)$ compared to cocoa shell (fermented) and pith extracts against A549 and MDAMDB-123 respectively but, there were no significant difference $(\mathrm{P}>0.05)$ of antiproliferative activity between cocoa leaf extract against MCF-7 with cocoa cherelle, shell (fermented) and shell unfermented against HeLa, HepG2 and HT29 respectively Table 1 . This could be due to the synergistic effects of the various components present in the extracts and previous report also showed that crude plant extracts are more active pharmacologically than their isolated active principles [23]. Furthermore, extract from Theobroma cacao especially cocoa bean also reported to possessed anticancer agents against various cancer cell lines due to the polyphenolic contents such as procyanidin present in the cocoa [24]. For further analysis, methanolic cocoa leaf extract was selected to determine the active compounds in the extract that contributed for potent anticancer activity against breast cancer cell (MCF-7).

\section{Extraction and yield of cocoa leaf}

Extraction is the important first step to analyse the bioactive

\begin{tabular}{|c|c|c|}
\hline Cancer Cells & Cocoa Extracts & IC $_{50}$ values $(\boldsymbol{\mu g} / \mathbf{m l})$ \\
\hline Lung (A549) & Shell (Fermented) & $520.67 \pm 19.06^{\mathrm{a}}$ \\
\hline Cervical (HeLa) & Cherelle & $67.80 \pm 9.36^{\mathrm{b}}$ \\
\hline Liver (HepG2) & Shell (Fermented) & $68.90 \pm 10.18^{\mathrm{b}}$ \\
\hline Colon (HT-29) & Shell (Unfermented) & $163 \pm 18.58^{\mathrm{b}}$ \\
\hline $\begin{array}{c}\text { Breast estrogen receptor positive } \\
\text { (MCF-7) }\end{array}$ & Leaf & $41.43 \pm 3.28^{\mathrm{b}}$ \\
\hline $\begin{array}{c}\text { Breast estrogen receptor negative } \\
\text { (MDA-MDB-123) }\end{array}$ & Pith & $360.00 \pm 34.77^{\mathrm{c}}$ \\
\hline
\end{tabular}

Note: a,b,c: The results of $\mathrm{IC}_{50}$ values indicates significant difference between six cancer cell lines, $P<0.05$. Results are means \pm SEM of triplicates experiments Table 1: Cocoa plant part extracts of Theobroma cacao with potent anticancer activities $\left(\mathrm{IC}_{50}\right.$ values) against various cancer cell lines. compounds in plant materials in order to extract the desired chemical components for further separation and characterization. In this study, cocoa leaf powder $(1 \mathrm{~kg})$ of Theobroma cacao was first extracted in methanol $(10 \mathrm{~L})$ for 3 days in room temperature by soaking method and provided $6.73 \%$ (67.3 g) yield with demonstrated $\mathrm{IC}_{50}$ value of 41.43 $\mu \mathrm{g} / \mathrm{ml}$. As mentioned by Chan [25] the excessive extraction time is not needed to extract more compounds and prolonged the process will lead to the oxidation process due to light or oxygen exposure. Then, successive solvent-solvent partition of crude methanol extract from cocoa leaf was performed first in hexane, dichloromethane and methanol produced $\mathrm{IC}_{50}$ values about $66.67 \pm 7.95 \mu \mathrm{g} / \mathrm{ml}, 100.60 \pm 2.40 \mu \mathrm{g} / \mathrm{ml}$ and $586.00 \pm$ $8.72 \mu \mathrm{g} / \mathrm{ml}$ respectively. The yields of liquid-liquid partitions for hexane, dichloromethane and methanol were gave approximately $20.65 \%$ yield $(13.90 \mathrm{~g}), 6.84 \%$ (4.62 g) and $30.16 \%(20.34 \mathrm{~g})$ respectively. The hexane partitioned fraction from liquid-liquid partition was found to be most active compared to other partitioned fractions against breast cancer cell line (MCF-7), while the methanol partitioned fraction showed the higher yield compared to partitioned fractions Figure 2. Based on the trends of results, it could be suggested that polar organic solvent was powerful to recover a higher extraction yield of anticancer components from Theobroma cacao leaf and thus might be considered in future extraction studies. However, it is important to point out that optimal extraction yield may not translate to higher anticancer activity where the polar solvent may just solubilise a larger range of compounds, some of which may have little or no anticancer activity [26]. As the result, only the hexane partitioned fraction was selected for purification using flash column chromatography based on biological activity. The results generated from three phases of fractionation process indicated that fractionation-1 (II/F4) Table 2, fractionation-2 (II/F7) Table 3 and fractionation-3 (II/F8) Table 4 demonstrated the yield values were $1,248.10 \mathrm{mg}, 220.60 \mathrm{mg}$ and $68.60 \mathrm{mg}$ respectively possessed the highest antiproliferative activity. As stated in Figure 2, the yield values of fractions decreasing when further fractionation process was carried out due to less

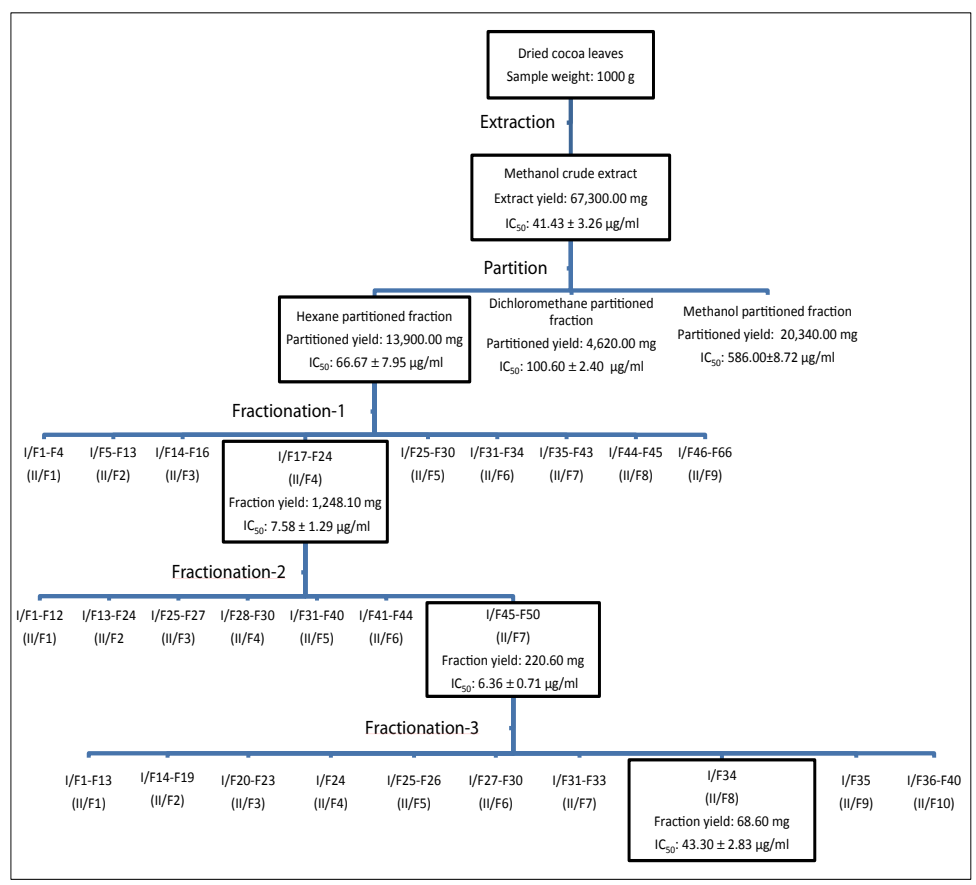

Figure 2: Diagram shows the bioassay guided fractionation process comprised the preparation of crude methanolic extract of Theobroma cacao leaf, liquid-liquid partitions, fractionation-1, fractionation-2 and fractionation-3. Samples preparations were carried out using rotary evaporator at $40^{\circ} \mathrm{C}$. TLC results were used to combine the fractions. Dry weight basis and antiproliferative activity were indicated in parentheses. 


\begin{tabular}{|c|c|c|}
\hline Fractions & TLC Mobile Phase & IC $_{50}(\boldsymbol{\mu g} / \mathbf{m l})$ \\
\hline II/F1 (I/F1-F4) & C:M - 9:1 & $66.67 \pm 6.44^{\mathrm{a}}$ \\
\hline II/F2 (I/F5-F13) & C:M - 9:1 & $70.30 \pm 10.52^{\mathrm{a}}$ \\
\hline II/F3 (I/F14-F16) & C:EA:M - 1:5:4 & $52.63 \pm 6.35^{\mathrm{a}}$ \\
\hline II/F4 (I/F17-F24) & H:C:EA - 4:5:1 & $7.58 \pm 1.29^{\mathrm{b}}$ \\
\hline II/F5 (I/F25-F30) & H:C:EA - 4:5:1 & $43.50 \pm 3.48^{\mathrm{a}}$ \\
\hline II/F6 (I/F31-F34) & H:C:EA - 4:5:1 & $60.60 \pm 4.86^{\mathrm{a}}$ \\
\hline II/F7 (I/F35-F43) & H:C:EA - 4:5:1 & $47.17 \pm 5.20^{\mathrm{a}}$ \\
\hline II/F8 (I/F44-F45) & H:C:EA - 4:5:1 & $52.60 \pm 3.47^{\mathrm{a}}$ \\
\hline II/F9 (I/F46-F66) & DCM:M - 1:9 & $45.70 \pm 2.00^{\mathrm{a}}$ \\
\hline
\end{tabular}

Note: $a, b$ Values are means of three replicate samples $(n=3)$. Data is presented as mean \pm SEM. Means followed by different letters within a column are significantly different according to Tukey HSD Test $(p<0.05)$

Table 2: The weight, the TLC mobile phase and the growth inhibitory activity of active fractions from fractionation-1 of Theobroma cacao leaf.

\begin{tabular}{|c|c|c|}
\hline Subfractions & TLC Mobile Phase & IC $_{50}$ ( $\mathbf{~ g / m l )}$ \\
\hline II/SF1 (I/SF1-F12) & H:C:EA - 4:5:1 & $42.07 \pm 2.65^{\mathrm{a}, \mathrm{c}, \mathrm{d}}$ \\
\hline II/SF2 (I/F13-F24) & H:C:EA - 4:5:1 & $50.27 \pm 1.48^{\mathrm{a}}$ \\
\hline II/SF3 (I/SF25-F27) & H:C:EA - 4:5:1 & $43.90 \pm 7.31^{\mathrm{a}}$ \\
\hline II/SF4 (I/SF28-F30) & H:C:EA - 4:5:1 & $18.70 \pm 1.04^{\mathrm{b}, \mathrm{c}, \mathrm{d}}$ \\
\hline II/SF5 (I/SF31-F40) & H:C:EA - 4:5:1 & $40.67 \pm 2.92^{\mathrm{a}, \mathrm{c}, \mathrm{d}}$ \\
\hline II/SF6 (I/SF41-F44) & H:C:EA - 4:5:1 & $36.47 \pm 3.52^{\mathrm{a}, \mathrm{c}, \mathrm{d}}$ \\
\hline II/SF7 (I/SF45) & H:C:EA - 4:5:1 & $6.36 \pm 0.71^{\mathrm{b}}$ \\
\hline
\end{tabular}

Note: ${ }^{a, b, c, d}$ Values are means of three replicate samples $(n=3)$. Data is presented as mean \pm SEM. Means followed by different letters within a column are significantly different according to Tukey HSD Test $(p<0.05)$

Table 3: The weight, the TLC mobile phase and the growth inhibitory activity of active fractions from fractionation-2 of Theobroma cacao leaf.

\begin{tabular}{|c|c|c|}
\hline Subsubfractions & TLC Mobile Phase & IC $_{50}(\boldsymbol{\mu g} / \mathbf{m l})$ \\
\hline II/SSF1 (I/SSF1-13) & H:C:Eth - 4:5:1 & $0.00^{\mathrm{c}}$ \\
\hline II/SSF2 (I/SSF14-19) & H:C:Eth - 4:5:1 & $0.00^{\mathrm{c}}$ \\
\hline II/SSF3 (I/SSF20-23) & H:C:Eth - 4:5:1 & $0.00^{\circ}$ \\
\hline II/SSF4 (I/SSF24) & H:C:Eth - 4:5:1 & $77.50 \pm 2.68^{\mathrm{b}}$ \\
\hline II/SSF5 (I/SSF25-F26) & H:C:Eth - 4:5:1 & $71.87 \pm 3.88^{\mathrm{b}}$ \\
\hline II/SSF6 (I/SSF27-30) & H:C:Eth - 4:5:1 & $0.00^{\mathrm{c}}$ \\
\hline II/SSF7 (I/SSF31-33) & H:C: $:$ th - 4:5:1 & $0.00^{\mathrm{c}}$ \\
\hline II/SSF8 (I/SSF34) & H:C:Eth - 4:5:1 & $43.30 \pm 2.83^{\mathrm{a}}$ \\
\hline II/SSF9 (I/SSF35) & H:C:Eth - 4:5:1 & $0.00^{\mathrm{c}}$ \\
\hline II/SSF10 (I/SSF36-40) & H:C: :th - 4:5:1 & $0.00^{\mathrm{c}}$ \\
\hline
\end{tabular}

Note: ${ }^{a, b, c}$ Values are means of three replicate samples $(n=3)$. Data is presented as mean \pm SEM. Means followed by different letters within a column are significantly different according to Tukey HSD Test $(p<0.05)$

Table 4: The weight, the TLC mobile phase and the growth inhibitory activity of active fractions from fractionation- 3 of Theobroma cacao leaf.

volume of fractions used. Solvent extractions are the most commonly used procedures to prepare extracts from plant materials due to their ease of use, efficiency, and wide applicability. It is generally known that the yield of chemical extraction depends on the type of solvents with varying polarities, extraction time and temperature, sample-to-solvent ratio as well as on the chemical composition and physical characteristics of the samples [27].

\section{Bioactivity guided fractions and isolation of Theobroma cacao leaf extract}

In this study, initial purification process were performed on crude methanolic extract of Theobroma cacao leaf in order to improve for the selective antiproliferative bioactive fraction using cell line antiproliferation assay as a guide [28]. The sequential solvent partitioning in three different polarity solvents were used to further fractionate the cocoa leaf extract. Hexane partitioned fraction, dichloromethane partitioned fraction and methanol partitioned fraction were obtained and showed significant antiproliferative bioactivity on breast cancer cell line (MCF-7) tested by MTT assay Figure 3. However, the non-polar solvent of hexane was demonstrated the most effective activity against MCF-7 with $\mathrm{IC}_{50}$ value of $66.67 \pm$ $7.95 \mu \mathrm{g} / \mathrm{ml}$ compared to dichloromethane and methanol. Solvent partitioning is important to obtain active compounds in the active extract that distributed according to their polarity and extensively used for fractionation following bioactivity guided fractionation [29]. Thus, the hexane partitioned fraction was for further fractionated by flash column chromatography with elution based upon solvents of increasing polarity. About 66 eluted fractions (I/F1-F66) from fractionation-1 were collected and chromatographed in thin layer chromatography (TLC) by to generate 9 combined fractions (II/F1-F9). Nine combined fractions were tested against MCF-7 and revealed that combined fraction II/F4 showed most potent antiproliferative activity at $\mathrm{IC}_{50}$ value of $7.58 \pm$ $1.29 \mu \mathrm{g} / \mathrm{ml}$ Table 2 . The fraction II/F4 was selected due to significantly difference $(\mathrm{P}<0.05)$ of $\mathrm{IC}_{50}$ value compared to other fractions illustrated in Table 3 for further purification by eluted again in solvent with increasing polarity generated about 45 eluted fractions (I/F1-F45) from fractionation- 2 and chromatographed in TLC to generate 7 combined fractions (II/F1-F7). Seven combined fractions were tested against MCF-7 and revealed that combined fraction II/F7 showed most potent antiproliferative activity at $\mathrm{IC}_{50}$ value of $6.36 \pm 0.71 \mu \mathrm{g} / \mathrm{ml}$ compared to other fractions. Lastly, the fraction II/F7 from fractionation-2 was selected due to significantly difference $(\mathrm{P}<0.05)$ of $\mathrm{IC}_{50}$ value compared to other fractions illustrated in Table 3 for further purification using flash column chromatography and eluted in series of solvents with increasing polarity to generate 10 combined fractions (II/F1-F10) from fractionation-3. The 10 combined fractions were tested against MCF-7 and revealed that fraction II/F8 showed most potent antiproliferative activity at $\mathrm{IC}_{50}$ value of $43.30 \pm 2.83 \mu \mathrm{g} / \mathrm{ml}$ (Table 4). However, based on the pattern of results presented here, it is possible that antiproliferative activity in fraction II/F7 (fractionation-2) is derived from combination of compounds and this fraction was selected for identified anticancer agents using GC-MS due to synergistic effect against breast cancer cell line $(\mathrm{MCF}-7)$ and also showed significantly difference $(\mathrm{p}<0.05)$ of $\mathrm{IC}_{50}$ value compared to fraction II/F8 (fractionation-3) displayed in Table 5. In the future study, the fractional inhibitory concentration index (FICI) method could be applied to determine the level of synergy and antagonism [28]. In this study, the cytotoxic effects for hexane partitioned fraction, fraction (II/F7) from fractionation-1, fraction (II/F8) from fractionation-2 and fraction (II/F8) from fractionation-3 against normal embryonic liver cell line (WRL68) were presented in Table 5. The $\mathrm{IC}_{50}$ value of hexane partitioned fraction, fraction (II/F4) from fractionation-1, fraction (II/F4) from fractionation-2 and fraction (II/F8) from fractionation-3 against embryonic liver cell line (WRL68)

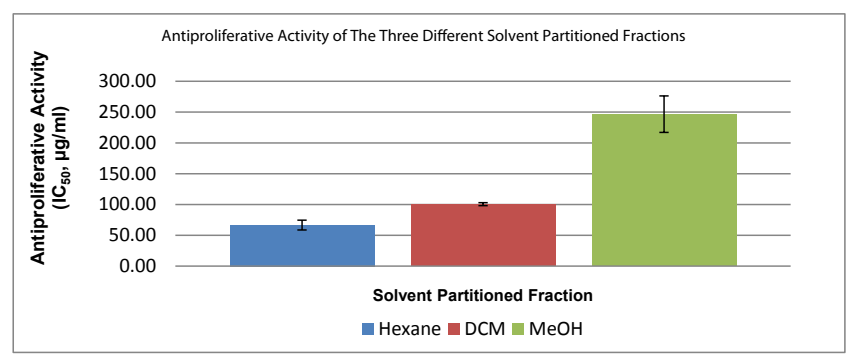

Figure 3: The $\mathrm{IC}_{50}$ values $(\mu \mathrm{g} / \mathrm{ml})$ of the three different solvent partitioned fractions against breast cancer cell line (MCF-7) by MTT assay. Values are means of three replicate samples $(n=3)$. Data is presented as mean \pm SEM. 


\begin{tabular}{|c|c|c|}
\hline Sample name & \begin{tabular}{c|}
$\mathrm{IC}_{50}(\mu \mathrm{g} / \mathrm{ml})$ \\
(Cancer cell - MCF-7) \\
\end{tabular} & $\begin{array}{c}\mathrm{IC}_{50}(\mu \mathrm{g} / \mathrm{ml}) \\
\text { (Normal cell - WRL68) }\end{array}$ \\
\hline Hexane partitioned fraction & $66.67 \pm 7.95$ & $651.33 \pm 5.36$ \\
\hline Fractionation-1 (II/F4) & $7.58 \pm 1.29$ & $51.70 \pm 3.33$ \\
\hline Fractionation-2 (II/F7) & $6.36 \pm 0.71$ & $44.0 \pm 1.76$ \\
\hline Fractionation-3 (II/F8) & $43.30 \pm 2.83$ & 0.00 \\
\hline
\end{tabular}

Note: ${ }^{a, b}$ Values are means of three replicate samples $(n=3)$. Data is presented as mean \pm SEM

Table 5: Antiproliferative activity of hexane partitioned fraction, fractionation-1 (II/ F4), fractionation-2 (II/F7) and fractionation-3 (II/F8) against breast cancer cell line (MCF-7) and liver normal cell line (WRL68).

\begin{tabular}{|c|c|l|c|}
\hline \multirow{2}{*}{ No. } & \multirow{2}{*}{ Test } & \multicolumn{2}{|c|}{ Phytochemical Screening } \\
\cline { 3 - 4 } & & $\begin{array}{l}\text { Methanolic Cocoa } \\
\text { Leaf Extract }\end{array}$ & $\begin{array}{l}\text { Hexanolic Cocoa Leaf } \\
\text { Partitioned Fraction }\end{array}$ \\
\hline 1 & Alkaloids & - & - \\
\hline 2 & Saponins & $1+$ & $1+$ \\
\hline 3 & Flavonoids & $1+$ & $1+$ \\
\hline 4 & Hydrolysable tannins & - & - \\
\hline & Condensed tannins & $2+$ & - \\
\hline 5 & Triterpenes & $2+$ & $1+$ \\
\hline 6 & Steroids & $2+$ & $3+$ \\
\hline
\end{tabular}

For saponins: $1+, 1-2 \mathrm{~cm}$ froth; $2+, 2-3 \mathrm{~cm}$ froth; and $3+,>3 \mathrm{~cm}$ froth.

For flavonoids, tannins, triterpenes, and steroids: $1+$, weak colour; $2+$, mild colour; $3+$, strong colour.

For alkaloids: - and $1+$, negligible amount of precipitate; $2+$, weak precipitate; and $3+$, strong precipitate.

Table 6: Phytochemical constituents of methanolic cocoa leaf extract and hexanolic cocoa leaf partitioned fraction of Theobroma cacao.

were $651.33 \pm 5.36,51.70 \pm 3.33,44.0 \pm 1.76$ and $0.00 \mu \mathrm{g} / \mathrm{ml}$ respectively, whereas the $\mathrm{IC}_{50}$ value of hexane partitioned fraction, fraction (II/F4) from fractionation-1, fraction (II/F7) from fractionation-2 and fraction (II/F8) from fractionation-3 against breast estrogen receptor positive cancer cell line (MCF7) were $66.67 \pm 7.95,7.58 \pm 1.29,6.36 \pm 0.71$ and $43.30 \pm 2.83 \mu \mathrm{g} / \mathrm{ml}$ respectively. This suggests that the cocoa leaf extract was more toxic to cancer cell than on normal cell because higher extract concentration needed to inhibit or kill $50 \%$ of embryonic liver cell line (WRL68). As mentioned by Weesam Al-Rashidi [30], that low toxicity toward normal cell and high toxicity towards cancer cells proposed a good anticancer constituent of the plant extract. It also shows the plant extract possesses a cytotoxic effect on cancer without causing toxicity to normal cells. Cocoa leaf extract was selected for further chemicals screening and identification due to potent anticancer agent against breast cancer cell (MCF-7).

\section{Phytochemical analysis}

Preliminary phytochemical screening of the methanolic cocoa leaf extract and hexanolic cocoa leaf partitioned fraction of Theobroma cacao revealed the presence of different phytochemical classes as shown in Table 6. Phytochemical of methanolic cocoa leaf extract contained saponins, flavonoids, condensed tannins, polyphenolic, triterpenes, steroids and showed absent of alkaloids and hydrolysable tannins compounds. Phytochemicals of hexanolic cocoa leaf partitioned fraction contained saponins, flavonoids, triterpenes, steroids and showed absent of alkaloids, condensed tannins and hydrolysable tannins compounds. The result also indicated that steroids showed strongest precipitation with $3+$ found in hexanolic cocoa leaf partitioned fraction. But, for both samples showed the absent of alkaloids compounds Table 6 . The presence of various phytochemicals active compounds identified are known to have beneficial importance in medicinal properties especially useful in pharmaceutical and therapeutic activities. Plant based natural compounds can be obtained from any part of the tree such barks, leaves, roots, flowers, fruits, seeds and others [31,32]. This important information on phytochemical screening will be helpful as a primary platform for further study on pharmacological aspect in cocoa leaf extract. Alkaloids were not detected in this study plant. Alkaloids normally related with medicinal uses for centuries and one of their common bioactivity properties is their phytotoxicity and their absence in this plant able to lower the risk of poisoning by the plant [33] and this literature supported the results in Table 5 where cocoa leaf extract showed not toxic to normal cell line (WRL68) based on IC $_{50}$ values. Saponins and flavonoids were presence in both samples. Saponins are a mild detergent responsible for various pharmacological and therapeutic effects such as used in hypercholesterolemia, hyperglycemia, antioxidant, anticancer, antiinflammatory and weight loss, etc. [32]. However, flavonoids have been shown to exhibit the wide range of biological activities like antimicrobial, anti-inflammatory, antiangionic, analgesic, antiallergic, cytostatic and antioxidant properties. In human diet, flavonoids could reduce the risk of various cancer diseases [34]. Tannins are antiviral, antibacterial, anticancer and certain tannins are also able to inhibit HIV replication, sensitivity and diuretic [35]. Hydrolysable and condensed tannins were negative for methanolic cocoa leaf extract and hexanolic cocoa leaf partitioned fraction but positive for condensed tannins in methanolic cocoa leaf extract. The possible reason could be adduced is due to mode of extraction process. But the absent for both tannins in hexanolic cocoa leaf partitioned fraction will not reduce the medical efficacies of Theobroma cacao leaf. Triterpenes proved the antioxidant effect and has been shown that ursolic acid, oleanoic acid and other triterpenoids were efficient as antimicrobial, antiinflammatory, anticancer, antiplatelet aggregation, anti-Mycobaterium Tuberculosis and anti-HIV/AIDS [36]. Finally, steroids showed strongest precipitation in hexanolic cocoa leaf partitioned fraction suggests the ability of this plant play a role as hyperchlolesterolemic effects, antidiuretics, antileukemic, antipyretic, antifungal, hyponotic, muscle relaxant activities, anticancer and antiviral agents [37].

\section{Identification of anticancer agents by GC-MS}

The bioactive compounds in selected cocoa leaf fraction (II/ F7) from fractionation-2 Table 3 with high anticancer activity were identified using GC-MS analysis. Data generated from GC-MS was interpreted based on database of National institute Standard and Technology (NIST). The chromatogram of the GC-MS analysis was presented in Figure 4. The GC-MS analysis results clearly showed that about 10 major compounds ( $>1 \%$ area) existed in active fraction (II/F7) of Theobroma cacao leaf. The components of the fraction II/F7 such as compound name, retention time (RT), area percentage (\%), molecular weight $(\mathrm{g})$, compound formula and similarity percentage (\%) were summarized in Table 6 . The major compounds with synergistic effect for anticancer activity were dimethyl sulfone (1.26\%), 2-Cyclohexane1-one, 4-(1-methyl) (1.53\%), phenol,2,4-bis(1,1-dimethylethyl) (16.26\%), 7-Oxabicyclo[4.1.0]heptane, 1-methyl-4-(2-methyloxiranyl)

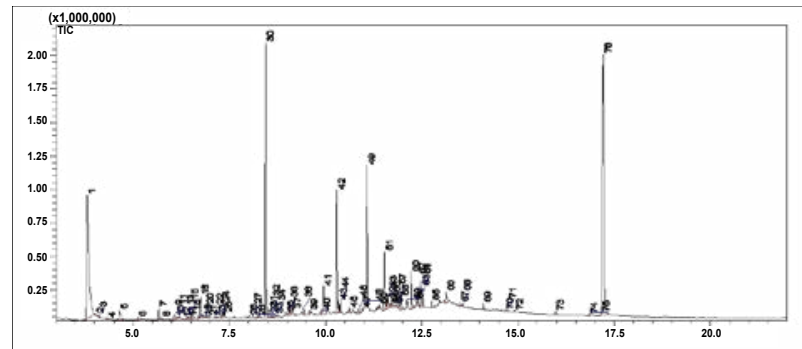

Figure 4: GC-MS mass spectral profile of fraction (II/F7) of Theobroma cacao leaf. 
(2.43\%), hexadecanoic acid, methyl ester (7.00\%), Octadecanoic acid, methyl ester (7.34\%), Hexadecanoic acid, 2-hydroxyethyl ester (4.24\%), Octadecanoic acid, 2-hydroxyethyl ester (2.39\%), Hexadecanoic acid, 2-hydroxy-1-(hydroxymethyl) ethyl ester (1.45\%) and lastly unknown (33.08\%). The unknown compound existed in this fraction II/F7 with highest percentage of area and needs further structural identification. The active compounds identified in fraction II/F7 of Theobroma cocoa leaf are medicinally valuable and possess various pharmaceutical applications mentioned in Table 7 . The presence phenol,2,4-bis $(1,1-$ dimethylethyl) attributes to the antioxidant and antibacterial [38]. Compounds such as and octadecanoic acid, methyl ester have been reported possessed antioxidant, hypercholesterolemic and pesticide [38] and for hexadecanoic acid, methyl ester possessed antiinflammatory, antiandrogenic cancer preventive, dermatitigenic ypocholesterolemic, 5-Alpha reductase inhibitor, anemiagenic insectifuge and flavour [39]. Compound hexadecanoic acid, 2-hydroxyethyl ester possessed antioxidant, hypocholesterolemic, nematicide, antiandrogenic and 5-Alpha reductase inhibitor [40]. Compound octadecanoic acid, 2-hydroxyethyl ester possessed anti androgenic, hypocholesteolemic, nematicide, 5-Alpha reductase inhibitor, antiacen, anti-inflammatory, antiandrogenic, cancer preventive and dermatitigenic [41] and lastly, compound hexadecanoic acid, 2-hydroxy-1-(hydroxymethyl)ethyl ester possessed hemolytic, pesticide, flavour and antioxidant. For unknown compound need further chemical structure confirmation using nuclear magnetic resonance (NMR).

\section{Conclusion}

Plants as sources of natural active compounds have remarkable pharmaceutical and the therapeutic potentials for human health. Plants are the great sources of secondary metabolites with various biological activities contributed by variety of phytochemical properties. In the present study, cocoa leaf of Theobroma cacao was the best extract as anticancer agent due to potent antiproliferative activity against breast cancer cell line (MCF-7) compared to other cocoa plant parts. Phytochemical screening of crude methanolic cocoa leaf extract reveals the presence of various secondary metabolites like flavonoids, saponins, tannins, triterpene, polyphenolics and steroids but absent in alkaloids. The strategy of bioactivity guided fractionation and isolation was used to purified and identify the most active anticancer activity from the methanolic cocoa leaf extract. From solvent partitioning process, the hexane partitioned fraction revealed the highest antiproliferative activity against MCF-7 and further purified in column chromatography to produce active fractions II/F4, II/F7 and II/F8 from fractionation-1, fractionation-2 and fractionation-3 respectively. Based on the $\mathrm{IC}_{50}$ values, it was obvious that fraction II/ F7 from fractionation-2 presented the highest antiproliferative activity with synergistic effects and 10 major chemical constituents were identified from cocoa leaf of Theobroma cacao by GC-MS analysis. In future, further study on unknown compound presented in active fraction II/F7 (fractionation-2) need to be further characterized using nuclear magnetic resonance (NMR) and isolation and identification of individual constituents also needed where the bioactive compounds could serve as natural resources for anticancer drug development research.

\section{Acknowledgement}

The authors would like to thank the Malaysian Cocoa Board (MCB) and cocoa smallholder for identification and supplying plant specimens and the Department of Biomedical Sciences, Universiti Putra Malaysia (UPM) for providing human cancer cell lines and the laboratory facilities. This work was financially supported by the Temporary Research Fund of MCB.

\section{References}

1. Young AM (1994) The chocolate tree: A Natural history of cacao. Smithsonian Institution Press, Washington, London.

2. Coe SD, Coe MD (1996) The true history of chocolate. Thames and Hudson, New York, USA.

3. Knight I (1999) Chocolate and cocoa: Health and nutrition (1st edition). Oxford UK: Blackwell Science.

4. Dillinger TL, Barriga P, Escárcega S, Jimenez M, Salazar Lowe D, et al. (2000) Food of the gods: cure for humanity? A cultural history of the medicinal and ritual use of chocolate. J Nutr 130: 2057S-72S.

5. Corti R, Flammer AJ, Hollenberg NK, Lüscher TF (2009) Cocoa and cardiovascular health. Circulation 119: 1433-1441.

6. Sánchez-Rabaneda $F$, Jáuregui $O$, Casals I, Andrés-Lacueva C, IzquierdoPulido M, et al. (2003) Liquid chromatographic/electrospray ionization tandem mass spectrometric study of the phenolic composition of cocoa (Theobroma cacao). J Mass Spectrom 38: 35-42.

7. Yamagishi M, Natsume M, Osakabe N, Okazaki K, Furukawa F, et al. (2003) Chemoprevention of lung carcinogenesis by cacao liquor proanthocyanidins in a male rat multi-organ carcinogenesis model. Cancer Lett 191: 49-57.

8. Kenny T, Keen C, Jones P, Kung H, Schmitz H, et al. (2004) Pentameric procyanidins isolated from Theobroma cacao seeds selectively down regulate ErbB2 in human aortic endothelial cells. Exp Biol Med 229: 255-263.

9. Kang NJ, Lee KW, Lee DE, Rogozin EA, Bode AM, et al. (2008) Cocoa procyanidins suppress transformation by inhibiting mitogen-activated protein kinase kinase. J Biol Chem 283: 20664-20673.

10. Carnésecchi S, Schneider Y, Lazarus SA, Coehlo D, Gossé F, et al. (2002) Flavanols and procyanidins of cocoa and chocolate inhibit growth and polyamine biosynthesis of human colonic cancer cells. Cancer Lett 175: 147-155.

11. Ramljak D, Romanczyk LJ, Metheny-Barlow LJ, Thompson N, Knezevic V, et al. (2005) Pentameric procyanidin from Theobroma cacao selectively inhibits growth of human breast cancer cells. Mol Cancer Ther 4: 537-546.

12. Lee KW, Kim YJ, Lee HJ, Lee CY (2003) Cocoa has more phenolic phytochemicals and a higher antioxidant capacity than teas and red wine. $J$ Agric Food Chem 51: 7292-7295.

13. Martin MA, Goya L, Ramos S (2013) Potential for preventive effects of cocoa and cocoa polyphenols in cancer. Food Chem Toxicol 56: 336-351.

14. Abdah MA, Ling LC, Rahmat A, Zakaria ZA (2011) Antioxidant and anti-proliferative activities of roselle juice on Caov-3, MCF-7, MDA-MB-231 and HeLa cancer cell lines. African Journal of Pharmacy and Pharmacology 5: 957-965.

15. Pan L, Lantvit DD, Riswan S, Kardono LB, Chai HB, et al. (2010) Bioactivityguided isolation of cytotoxic sesquiterpenes of Rolandra fruticosa. Phytochemistry 71: 635-640.

16. LudwiczukA, Saha A, Kuzuhara T, Asakawa Y (2011) Bioactivity guided isolation of anticancer constituents from leaves of Alnus sieboldiana (Betulaceae) Phytomedicine 18: 491-498.

17. Forgo P, Zupkó I, Molnár J, Vasas A, Dombi G, et al. (2012) Bioactivity-guided isolation of antiproliferative compounds from Centaurea jacea L. Fitoterapia 83: 921-925.

18. Lai CS, Mas RH, Nair NK, Majid MI, Mansor SM, et al. (2008) Typhonium flagelliforme inhibits cancer cell growth in vitro and induces apoptosis: an evaluation by the bioactivity guided approach. J Ethnopharmacol 118: 14-20.

19. Ode OJ, Asuzu IU, Ajayi IE (2011) Bioassay-guided fractionation of the crude methanol extract of Cassia singueana leaves. Journal of Advanced Scientific Research 2: 81-86.

20. Hema R, Kumaravel S, Gomathi S, Sivasubramaniam C (2010) Gas chromatography-mass spectroscopic analysis of Lawsonia inermis leaves. New York Science Journal 3: 141-143.

21. Atjanasuppat K, Wongkham W, Meepowpan P, Kittakoop P, Sobhon P, et al. (2009) In vitro screening for anthelmintic and antitumour activity of ethnomedicinal plants from Thailand. J Ethnopharmacol 123: 475-482.

22. Mani S, Krishnaswamy M (2010) Antitumor potential of total alkaloid extract from Tabebuia rosea. Nature and Science 8: 77-85. 
23. Karagoz A, Turgut-Kara N, Cakir O, Demirgan R, Ari S (2007) Cytotoxic activity of crude extracts from Astragalus chrysochilorus (Leguminosae). Biotechnology \& Biotechnological Equipment 21: 220-222.

24. Jiyoung K, Ki Won L, Hyong JL (2011) Cocoa (Theobroma cacao) seeds and phytochemicals in human health. Nuts \& Seeds in Health and Disease Prevention 351-360.

25. Chan SW, Lee CY, Yap CF, Wan Aida WM, Ho CW (2009) Optimisation of extraction conditions for phenolic compounds from Limau purut (Citrus hystrix) peels. International Food Research Journal 16: 203-213.

26. Anwar F, Kalsoom U, Sultana B, Mushtaq M, Mehmood T, et al. (2013) Effect of drying method and extraction solvent on the total phenolics and antioxidant activity of cauliflower (Brassica oleracea L.) extracts. International Food Research Journal 20: 653-659.

27. Dai J, Mumper RJ (2010) Plant phenolics: extraction, analysis and their antioxidant and anticancer properties. Molecules 15: 7313-7352.

28. Umthong S, Phuwapraisirisan P, Puthong S, Chanchao C (2011) In vitro antiproliferative activity of partially purified Trigona laeviceps propolis from Thailand on human cancer cell lines. BMC Complimentary and Alternative Medicine 11: 1-8.

29. Duarte K, Rocha-Santos TAP, Freitas AC, Duarte AC (2012) Analytical techniques for discovery of bioactive compounds from marine fungi. Trends in Analytical Chemistry 34: 97-110.

30. Weesam Al Rashidi, Supri M, Nurhada Manshoor (2011) Cytotoxic activity of crude extract from Costus tieanus (Costaceae). American-Eurasian Journal of Toxicological Sciences 3: 63-66.

31. Gordon DM (2001) Geographical structure and host specificity in bacteria and the implications for tracing the source of coliform contamination. Microbiology 147: 1079-1085

32. Mithraja MJ, Marimuthu Antonisamy J, Mahesh M, Paul ZM, Jeeva S (2011)
Phytochemical studies on Azolla pinnata R. Br., Marsilea minuta L. and Salvinia molesta. Mitch. Asian Pacific Journal of Tropical Biomedicine S26-S29.

33. Aiyegoro OA, Okoh Al (2010) Preliminary phytochemical screening and in vitro antioxidant activities of the aqueous extract of Helichrysum longifolium DC BMC Complement Altern Med 10: 21.

34. Hodek P, Trefil P, Stiborová M (2002) Flavonoids-potent and versatile biologically active compounds interacting with cytochromes P450. Chem Biol Interact 139: 1-21

35. Daniel UN, Ohalete CN, Nnoli MC (2012) Phytochemical screening for active compounds in leaves, bark and seed extracts of Azadirachta indica in Owerri, Imo State, South-Eastern Nigeria. World Journal of Pharmacy and Pharmaceutical Sciences 1: 1181-1188.

36. Babalola IT, Shode FO (2013) Ubiquitous Ursolic Acid: A Potential Pentacyclic Triterpene Natural Product. Journal of Pharmacognosy and Phytochemistry 2 : 214-222.

37. Aiyegoro OA, Okoh Al (2009) Phytochemical screening and polyphenolic antioxidant activity of aqueous crude leaf extract of Helichrysum pedunculatum. Int J Mol Sci 10: 4990-5001.

38. Manorenjitha MS, Norita AK, Norhisham S, Asmawi MZ (2013) GC-MS analysis of bioactive components of Ficus Religiosa (Linn) Stem. International Journal of Pharmacology and Biological Sciences 4: 99- 103.

39. Kalaisezhiyen P, Sasikumar V (2012) GC-MS evaluation of chemical constituent from methanolic leaf extract of Kedrostis foetidissima (Jacq.) Cogn. Asian Journal of Pharmaceutical and Clinical Research 5: 77-81.

40. Sheela D, Uthayakumari F (2013) GC-MS analysis of bioactive constituents from coastal sand dune taxon-Sesuvium portulacastrum (L.). Bioscience Discovery 4: 47-53.

41. Elezabeth VD, Arumugam S (2014) GC - MS Analysis of ethanol extract of Cyperus rotundus leaves. International Journal of Current Biotechnology 2: 19-23. 